\title{
Experimental measurements of the aerosol optical depth of atmosphere on the southeast coast of Lake Baikal
}

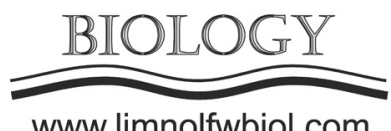

www.limnolfwbiol.com

\author{
Dementeva A.L.*, Zhamsueva G.S., Zayakhanov A.S., Tsydypov V.V. \\ Institute of Physical Materials Science, Siberian Branch of the Russian Academy of Sciences, Sakhyanovoi Str., 6, Ulan-Ude, 670047, \\ Russia
}

\begin{abstract}
Based on long-term measurements of the aerosol optical depth of the Baikal region atmosphere (Tory station and the Boyarsky station), the optical characteristics of the atmospheric aerosol are analyzed. The research results showed that the annual variation of the atmosphere spectral transparency in the Baikal region is mainly formed under the influence of natural sources of aerosols. It was revealed that in the long-term course of average monthly AOD values of the st. Tory atmosphere for 2012-2019 the spring maximum decreased, while the summer maximum increased, because the frequency and duration of forest fires increased during the summer months.
\end{abstract}

Keywords: Aerosol optical depth, atmosphere, smoke aerosol, transport, Baikal

The atmosphere transparency has a significant effect on the flow of solar radiation coming to the earth's surface. The contribution of the aerosol component to the atmosphere transparency varies significantly depending on the geographical location, meteorological factors, the nature of the underlying surface, the influence of natural and anthropogenic sources of aerosol entry into the atmosphere (Issledovaniye..., 2012). Therefore, regular network observations of atmospheric transparency in various regions of the globe play an important role in understanding the laws of variability of atmosphere radiation-active components. In recent years, studies of the optical and microphysical characteristics of smoke from forest fires are relevant due to their long-distance transport and the impact on changes in radiation forcing and climate in regions affected by smoke (Zhu et al., 2018). To identify the basic laws of the spatiotemporal variability of aerosol characteristics in the Baikal region atmosphere, experimental results of the aerosol optical depth (AOD) variations at the Boyarsky scientific station for the summer of 2019 were processed and analyzed using an SP-9 solar photometer and st. Tory according to the global network AERONET.

The research results showed that the annual variation of the spectral atmosphere transparency at the Baikal region is mainly formed under the influence of natural sources of aerosols. One of the most powerful sources of atmospheric aerosol affecting the annual course of AOD in the region is forest fires. Large-scale forest fires were observed in Siberia and the Republic of Sakha Yakutia and a high turbidity of the atmosphere at both stations due to forest fires, which is also confirmed by the measurement of vertical profiles of parameters of suspended particles by space-based lidar CALIOP on the satellite "CALIPSO" during the expeditionary measurements of 2019. Forest fires make a decisive contribution to the annual variation of the ultraviolet and visible regions of the AOD spectrum at the Baikal region.

In the long-term change in the fine dispersed AOD component, a growth tendency and very high variations due to the smoke of forest fires were noted. As known, according to earlier studies, the existence of a spring maximum of AOD atmosphere at station Tory from 2006 to 2012, the minimum values of AOD were observed in the summer and autumn months. But in recent years, as can be seen from Fig. 1B, in the long-term course of average monthly AOD values of the atmosphere Torah for 2012-2019 the spring maximum decreased, while the summer maximum increased, because the frequency and duration of forest fires increased during the summer months. On Fig. 1A is showed the average spectral dependences of AOD for July-August 2019 at station Boyarsky and Tory.

Thus the long-term variability of AOD was formed under the influence of frequent forest fires and a significant decrease in AOT in the spring.

This work was carried out with financial support in the framework of state assignment No. 03362019-0007 and with partial support from the Russian Foundation for Basic Research No. 19-05-50005 "Mikromir" in terms of AOD data processing. 


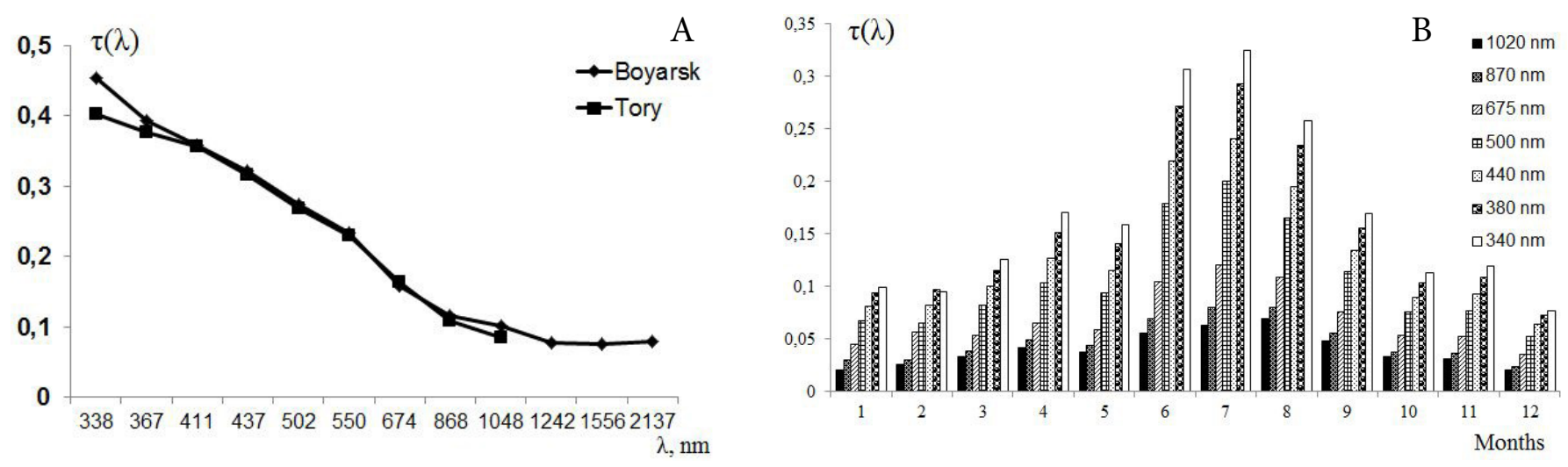

Fig.1. AOD average spectral dependences $\tau(\lambda)$ A st. Boyarsky in the summer, B st. Tory 2012-2019 years.

\section{References}

Zhu Q., Liu Y., Jia R. et al. A numerical simulation study on the impact of smoke aerosols from Russian forest fires on the air pollution over Asia. 2012. Atmospheric Environment 182: 263-274. DOI: 10.1016/j.atmosenv.2018.03.052
Issledovaniye radiatsionnykh kharakteristik aerozolya $\mathrm{v}$ Aziatskoy chasti Rossii [Study of radiative characteristics of aerosol in Asian part of Russia]. 2012. In: Sakerin S.M. (Ed.). Tomsk: IAO SB RAS. (in Russian) 